\title{
Genetic Variation and Trait Correlations for Fruit Weight, Firmness and Color Parameters in Wild Accessions of Fragaria chiloensis
}

\author{
Freddy Mora ${ }^{\mathbb{D}}$, Paz E. Zúñiga and Carlos R. Figueroa *(D) \\ Institute of Biological Sciences, Campus Talca, Universidad de Talca, Talca 3465548, Chile \\ * Correspondence: cfigueroa@utalca.cl; Tel.: +56-71-2200277
}

Received: 9 July 2019; Accepted: 27 August 2019; Published: 2 September 2019

\begin{abstract}
Fragaria chiloensis is an herbaceous perennial undomesticated species with a high potential for sustainable fruit production in areas where drought and salinity represent a constraint on crop growth and productivity. The present study aimed to examine the genetic variability of fruit weight, firmness and color parameters $\left(\mathrm{L}^{*}, \mathrm{a}^{*}, \mathrm{~b}^{*}\right.$, Hue angle and Chroma) in wild-collected accessions from south-central Chile. A Bayesian analysis of genetic parameters showed that the traits under study were found to be moderately to highly heritable with estimates from the marginal posterior distributions ranging between 0.26 (firmness) and $0.67\left(\mathrm{~L}^{*}\right)$. Interestingly, Hue and Chroma had relatively high values of broad-sense heritability, with the Bayesian credible set: $\mathrm{H}^{2}=0.53-0.76$ and $\mathrm{H}^{2}=0.42-0.66$, respectively. A Bayesian bi-trait analysis showed a positive genetic correlation $\left(\hat{r}_{\mathrm{g}}=0.65\right.$, probability of the posterior samples $\left.<0.05\right)$ between fruit weight and Hue, which agreed with the existence of two pleiotropic loci [from simple sequence repeats (SSR) markers FvH4045 and CFACT084 on linkage groups FG3A and FG2A/2B/2C] with probabilities of the posterior estimates of 0.022 and $<0.001$, respectively. According to the Bayesian credible region, 5 (of 12) correlation estimates were significantly different from zero. Hue and Chroma showed a high and negative genetic correlation ( $\left.\hat{r}_{g}=-0.762\right)$, but no significant pleotropic locus. The results are promising and suggest that the genetic variation found among wild populations of $F$. chiloensis supports the idea of domesticating this crop for sustainable fruit production systems.
\end{abstract}

Keywords: Chilean strawberry; domestication; fruit quality traits; genetic diversity; heritability

\section{Introduction}

Fragaria chiloensis (L.) Mill. ssp. chiloensis Staudt, is an herbaceous perennial undomesticated species native to Chile with two botanical forms: $\mathrm{f}$. chiloensis and f. patagonica. The patagonica form produces small berries of an intense red color and is distributed between latitudes $35^{\circ} \mathrm{S}$ and $45^{\circ} \mathrm{S}$ latitudes of Chile, whereas the chiloensis form is characterized by producing large berries and a white-pink color distributed between latitudes of $35^{\circ} \mathrm{S}$ and $39^{\circ} \mathrm{S}[1,2]$. The latter was anciently cultivated by the native peoples (Mapuches) [1], a time when its leaves and fruits were used for food and medicinal purposes. Currently, F. chiloensis ssp. chiloensis $\mathrm{f}$. chiloensis is cultivated on a small scale in coastal areas [1] where no breeding process has occurred. In fact, this strawberry species is still in an incipient domesticated stage, since no varieties exist, and there are limitations to the successful development as a large-scale crop because the plantations have a low yield and the berries are not uniform in size [1].

Fruit quality (including fruit flavor, color, texture, aroma and nutritional value) is a key factor for consumer acceptability and is therefore receiving increasing importance in several strawberry breeding programs [3-6]. In this sense, F. chiloensis has great agricultural and commercial potential due 
to its high nutritional value, its intense aroma and flavor, and the exotic color of its fruits [7]. In turn, the quality of fresh fruit depends to a great extent on the ripening stage, a complex and genetically controlled process that involves biochemical and physiological changes that result in the acquisition of color, texture, flavor and aroma of the fruits [8]. Chilean strawberries present a rapid softening during the ripening process, a factor that negatively affects their post-harvest life and reduces their quality [1,7]. Nevertheless, F. chiloensis fruits exhibit considerable differences between botanical forms both in morphological and skin color parameters [9] and the latter could be considered as a distinctive trait among traditional red color of domesticated Fragaria $\times$ ananassa Duch. fruits.

To date, the color diversity (along with fruit firmness and fresh weight) has not been characterized in a native germplasm collection of $F$. chiloensis. Thus, with the intention to start domestication and breeding programs that allow the development of F. chiloensis genotypes with higher fruit quality, especially with color variants and a longer postharvest life, the present study aimed to examine the genetic variation and trait correlations for fruit firmness, fresh weight, and color $\left(L^{*}, a^{*}, b^{*}\right.$, Hue angle and Chroma parameters) in wild populations of $F$. chiloensis $[2,10]$ from south-central Chile. Additionally, in order to examine the existence of pleotropic loci between two correlated traits, previously reported cross-species transfer of simple sequence repeats (SSR) markers in F. chiloensis [10] were used and analyzed individually according to a Bayesian bi-trait regression.

\section{Materials and Methods}

\subsection{Plant Material}

Ripe fruits of 391 ramets from 36 wild accessions of F. chiloensis (Figure 1, Table S1) were evaluated under nursery conditions (at the University of Talca, Chile, latitude $35^{\circ} 24^{\prime} \mathrm{S}$, longitude $71^{\circ} 38^{\prime} \mathrm{W}$ ) for fruit firmness (F), fresh weight $(W)$, and the color parameters $L^{*}, a^{*}, b^{*}$, Hue angle $\left(h^{\circ}\right)$ and Chroma, during the growing season in 2015. The ripe stages of $F$. chiloensis spp. chiloensis $\mathrm{f}$. chiloensis and f. patagonica were defined as previously reported [7,9]. The analyzed accessions (Table S1) correspond to a subset from the germplasm collection evaluated by Mora et al. [2] and Oñate et al. [10].

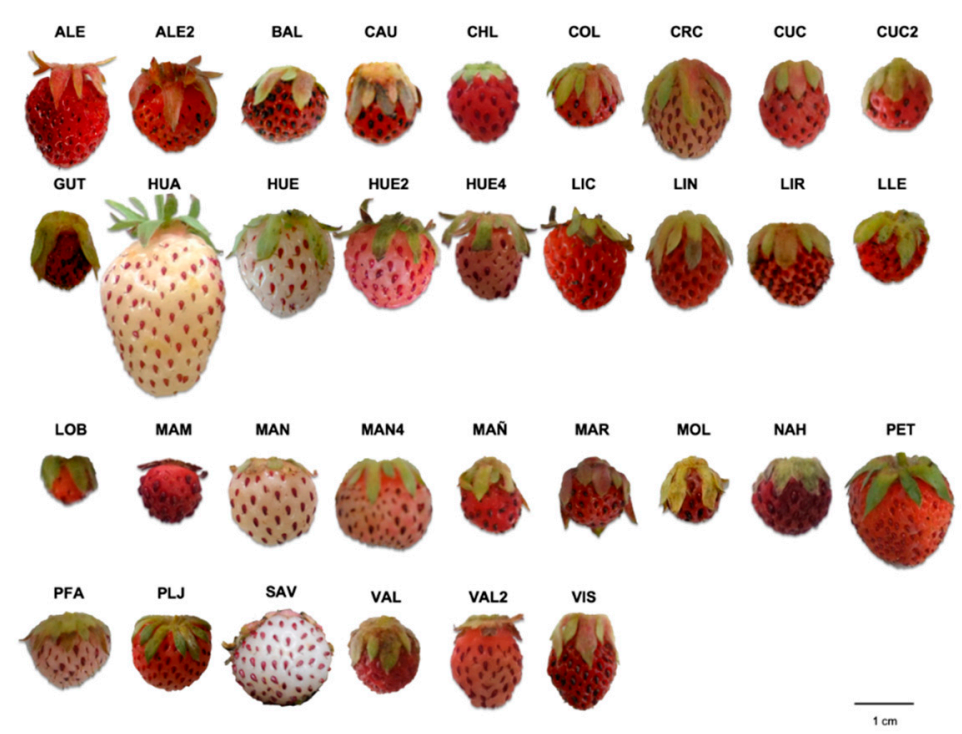

Figure 1. Representative fruits from a sample of wild accessions of Fragaria chiloensis spp. chiloensis $\mathrm{f}$. chiloensis (CRC, HUA, HUE, HUE2, HUE4, MAN, MAN4, PFA, SAV and VAL2) and f. patagonica (ALE, ALE2, BAL, CAU, CHL, COL, CUC, CUC2, GUT, LIC, LIN, LIR, LLE, LOB, MAM, MAÑ, MAR, MOL, NAH, PET, PLJ, VAL, and VIS) from the germplasm collection analyzed in the present research. Fruit images of accessions are ordered alphabetically. Full names and origins of accessions are in Table S1. 


\subsection{Measurement of Fruit Weight, Skin Color and Firmness}

Due to the undomesticated status of Fragaria chiloensis, this species typically exhibits irregular fruiting rates. For this reason, at least three (up to forty-four) fruits per accession were evaluated for fresh weight (g) in an analytical balance (model ENTRIS224-1s, Sartorius, Goettingen, Germany) and then skin colors were measured using a colorimeter (model CR-400, Konica Minolta, Tokyo, Japan) on opposite sides of each fruit on the equatorial side as technical replicates. The color parameters were expressed according to the CIE $1976 \mathrm{~L}^{*} \mathrm{a}^{*} \mathrm{~b}^{*}\left(\right.$ CIELAB) scale, where $\mathrm{L}^{*}, \mathrm{a}^{*}$, and $\mathrm{b}^{*}$ values indicate lightness (dark to light), index of redness (green $(-)$ to red $(+))$ and yellowness (blue $(-)$ to yellow $(+)$ ), respectively [11]. The dimensions of color Chroma $\left(C=\left(a^{* 2}+b^{* 2}\right)^{1 / 2}\right)$ and the Hue angle $\left(h^{\circ}=\arctan \right.$ $\left.\left(b^{*} / a^{*}\right)\right)$ were calculated from numerical values of $a^{*}$ and $b^{*}$, as previously reported [11].

Finally, fruit firmness was registered in Newton units (N) with measurements in opposite sides of each fruit using a texture analyzer (model CT3, Brookfield, MA, USA) with the especially designed TA-39 probe for firmness measurement of berries and small fruits.

\subsection{Genetic and Statistical Analyses}

A Bayesian analysis was carried out for the estimation of the variance components and genetic parameters using the following base model in a Bayesian framework according to Torres et al. [12]:

$$
\mathrm{y}=\mathrm{X} \beta+\mathrm{Zg}+\varepsilon
$$

where, $\mathrm{y}$ corresponds to the observation vector (a specific trait under study). $\mathrm{X}$ and $\mathrm{Z}$ are the known incidence matrices that relates the observation vector $(y)$ to the vectors $\beta$ and g, respectively. $\beta$ is a vector of the overall population mean, $g$ is the genotypic effect vector, and $\varepsilon$ is the residual effect vector.

The broad-sense heritability $\left(\mathrm{H}^{2}\right)$ was calculated for the traits under study using the following expression according to Falconer [13]:

$$
\hat{\mathrm{H}}^{2}=\hat{\sigma}_{g}^{2} /\left(\hat{\sigma}_{g}^{2}+\hat{\sigma}_{\varepsilon}^{2}\right)
$$

where, $\hat{\sigma}_{g}^{2}$ and $\hat{\sigma}_{\varepsilon}^{2}$ correspond to the genotypic and residual variances, respectively. The genetic association between each pair of traits measured in the same plant (ramet) was calculated from a bi-trait model, according to Falconer [13], using the following expression:

$$
\hat{r}_{g}=\hat{\sigma}_{g_{x y}} / \sqrt{\hat{\sigma}_{g_{x}}^{2}+\hat{\sigma}_{g_{y}}^{2}}
$$

where, $\hat{\sigma}_{g x y}^{2}$ corresponds to the estimation of the genetic covariance component between two pairs of traits $\times$ and $Y$ (posterior means), $\hat{\sigma}_{g_{x}}^{2}$ and $\hat{\sigma}_{g_{y}}^{2}$ are the posterior variances for each pair of traits under analysis. Deviance Information Criteria (DIC) was used for model comparisons, which defined by the following expression:

$$
\mathrm{DIC}=\overline{\mathrm{D}}+\mathrm{pD}
$$

where $\overline{\mathrm{D}}$ is a Bayesian measure of model fit, which is defined as the posterior expectation of the deviance $\left(\overline{\mathrm{D}}=E_{\theta / y}[-2 \cdot \ln f(y / \theta)]\right) ; \mathrm{pD}$ is the effective number of parameters. We compared the genetic model (1) with a null-model (without the genotype effect), and models with DIC differences (delta DIC) $>10$ were considered to be significantly supported against a null-model.

Additionally, in order to examine the existence of pleotropic loci between two correlated traits, thirty-nine SSR markers were assessed [10] (Table S2). These SSR primers yielded a total of 259 alleles, which were analyzed individually according to a Bayesian bi-trait regression (single-locus bi-trait model) [14]. The probability that a determined locus was associated jointly with two correlated traits (pleiotropic) was evaluated by the probability of the posterior estimates including zero in the Bayesian regression model (probability of Markov chain Monte Carlo; pMCMC). The residuals from a general 
linear model for each trait were used as the adjusted phenotypes for the Bayesian regression, taking into account the effect of genetic structure [10]. All the statistical analyses were performed using the $R$ package MCMCglmm (version 3.6.1; https://www.r-project.org) [15].

\section{Results and Discussion}

In this study, significant genetic variation was observed for all traits under study (Table 1, Figure 2, Table S3); specifically, each trait had a DeltaDIC $>10$, which provided decisive evidence against the model that considered a genotype effect equal to zero (i.e., null model M0: $y=X \beta$ ) (Table 1). Previous studies have shown low and moderate levels of genetic diversity among F. chiloensis germplasm collections, which generally depend on the size of the collection and the type of molecular marker used $[10,16,17]$.

Table 1. Model assessment based on the Deviance Information Criteria (DIC) for fruit weight (W, in g), firmness (F, in Newton), and the color parameters $\mathrm{L}^{*}, \mathrm{a}^{*}, \mathrm{~b}^{*}$, Hue angle $\left(\mathrm{h}^{\circ}\right)$ and Chroma measured in different wild accessions of Fragaria chiloensis.

\begin{tabular}{|c|c|c|c|c|c|c|c|}
\hline $\begin{array}{c}\text { Competitive } \\
\text { Models }\end{array}$ & Weight (g) & Firmness (N) & $\mathbf{L}^{*}$ & $a^{*}$ & $\mathbf{b}^{*}$ & Hue Angle $\left(h^{\circ}\right)$ & Chroma \\
\hline$y=X \beta(\mathrm{M} 0)^{1}$ & 1107.1 & -337.4 & 2685.2 & 2612.8 & 2290.3 & 2747.1 & 2627.2 \\
\hline$y=X \beta+Z g(M 1)^{2}$ & 854.5 & -381.6 & 2364.9 & 2324.5 & 2173.3 & 2535.5 & 2398.7 \\
\hline DeltaDIC $^{3}$ & 252.6 & 44.2 & 320.2 & 288.3 & 117.0 & 211.7 & 228.6 \\
\hline
\end{tabular}
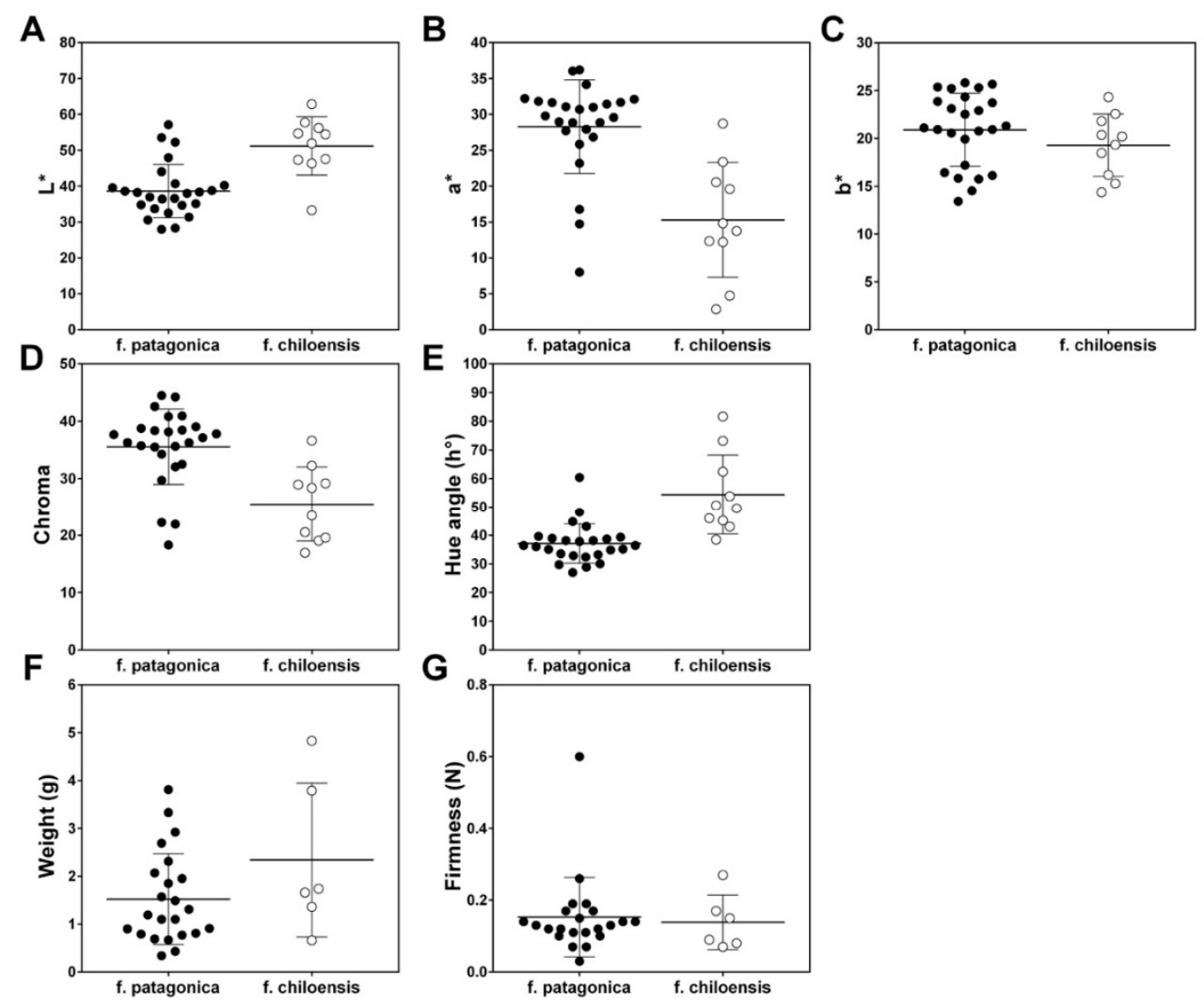

Figure 2. Distribution of phenotypic values for the seven fruit quality traits of different Fragaria chiloensis ssp. chiloensis f. patagonica (black dots) and f. chiloensis (open circles) accessions. Traits: in (A-E) the color parameters $\mathrm{L}^{*}, \mathrm{a}^{*}, \mathrm{~b}^{*}$, Hue angle $\left(\mathrm{h}^{\circ}\right)$ and Chroma, respectively; (F) Weight $(\mathrm{g})$, and $(\mathbf{G})$ Firmness (N) during the growing season in 2015. Each dot corresponds to a mean value for each accession trait. The horizontal bar shows to mean \pm standard deviation (SD). 
Based on the models selected according to the DIC (Table 1), the traits under study were found to be moderately to highly heritable, with estimates from the marginal posterior distributions ranging from 0.26 (firmness) to $0.67\left(\mathrm{~L}^{*}\right)$ (Table 2). For instance, Hue and Chroma had relatively high values of broad-sense heritability, with values of $\mathrm{H}^{2}=0.64$ and 0.54 , respectively. Fruit weight was a relatively highly heritable trait in this population $\left(\mathrm{H}^{2}=0.61\right.$, ranging from 0.49 to 0.74 , according to the Bayesian credible set) (Table 2). The high relative values of $\mathrm{H}^{2}$ found in the present study were probably related to the origin of the studied population. In this sense, in wild populations as in the current case, a great genetic variability could be captured, since no breeding process had been performed to date $[2,18]$.

Table 2. Bayesian estimates of the broad-sense heritability (posterior mean: $\mathrm{H}^{2}$, standard deviation: SD, lower and upper cutoffs for $90 \%$ credible sets), variance components (genetic variance: $\hat{\sigma}_{g}^{2}$; residual variance: $\hat{\sigma}_{\varepsilon}^{2}$ ) for fruit weight, firmness and the color parameters $L^{*}, a^{*}, b^{*}$, Hue angle and Chroma evaluated in Fragaria chiloensis.

\begin{tabular}{ccccccc}
\hline & \multicolumn{3}{c}{ Variance Components } & \multicolumn{3}{c}{ Broad Sense Heritability } \\
\cline { 2 - 7 } Trait & $\hat{\sigma}_{g}^{2}$ & $\hat{\sigma}_{\varepsilon}^{2}$ & $\mathbf{H}^{2}$ & SD & \multicolumn{2}{c}{ Credible Set } \\
\cline { 3 - 7 } & & & & & Lower & Upper \\
\hline Weight & 1.092 & 0.664 & 0.61 & 0.077 & 0.487 & 0.740 \\
Firmness & 0.006 & 0.017 & 0.26 & 0.087 & 0.113 & 0.394 \\
$\mathrm{~L}^{*}$ & 84.08 & 40.36 & 0.67 & 0.063 & 0.561 & 0.767 \\
$\mathrm{a}^{*}$ & 73.31 & 36.03 & 0.66 & 0.065 & 0.549 & 0.763 \\
$\mathrm{~b}^{*}$ & 11.22 & 24.01 & 0.31 & 0.071 & 0.201 & 0.433 \\
Hue angle & 120.7 & 65.15 & 0.64 & 0.070 & 0.528 & 0.756 \\
Chroma & 54.74 & 44.62 & 0.54 & 0.073 & 0.418 & 0.657 \\
\hline
\end{tabular}

Fruit weight and firmness are important traits both for the production and quality of strawberries, whose quality is sensitive to the market [19-21]. These results were consistent with those reported previously by Whitaker et al. [22] in a $F . \times$ ananassa breeding population, in which broad-sense heritability values ranged from 0.18 to 0.53 for fruit quality traits. Mora et al. [2] evaluated plant survival, flowering, fruit set, and ripening in 63 accessions, covering most of the natural geographic range of $F$. chiloensis in Chile. Within the results of that study it was found that the traits under analysis showed a low to moderate broad-sense heritability $\left(\mathrm{H}^{2}\right)$, varying from $\mathrm{H}^{2}=0.14$ for survival to $\mathrm{H}^{2}=0.4$ for fruit set, demonstrating the potential of $F$. chiloensis to be genetically improved. It should be noted the low fruit number analyzed in some accessions in the present research has been reported previously in a F. chiloensis germplasm collection and it could be related with self-incompatibility issues [2]. On the other hand, previous studies with $F . \times$ ananassa have estimated moderate to high heritability for traits such as firmness [23], ripening time and fruit weight [24], which are directly related to the fruit quality. Mishra et al. [5] reported a high variation among commercial strawberry genotypes for various fruit quality traits, such as fresh fruit weight, providing large opportunities for selection or breeding.

In addition, we estimated the genetic correlations (posterior means and credible set) between pairs of traits (Table 3). Some pairwise correlations were not performed since a dependency between parameters exists (i.e., in color the calculation of Hue and Chroma depends on $\mathrm{a}^{*}$ and $\mathrm{b}^{*}$ ).

Table 3. Posterior means of genetic correlations and $90 \%$ credible sets from marginal posterior distributions, calculated between pairs of traits in different wild accessions of Fragaria chiloensis.

\begin{tabular}{cccc}
\hline \multirow{2}{*}{ Pair of Traits } & \multirow{2}{*}{$\hat{r}_{g}$} & \multicolumn{2}{c}{ Credible Sets } \\
\cline { 3 - 4 } & & Lower & Upper \\
\hline Weight-Firmness & $-0.467^{1}$ & -0.822 & -0.119 \\
Firmness-Hue angle $^{3}$ & $-0.217^{2}$ & -0.693 & 0.236 \\
Firmness-Chroma $^{3}$ & $0.204^{2}$ & -0.175 & 0.599 \\
Weight-Hue angle $^{3}$ & $0.649^{1}$ & 0.414 & 0.878 \\
\hline
\end{tabular}


Table 3. Cont.

\begin{tabular}{cccc}
\hline \multirow{2}{*}{ Pair of Traits } & \multirow{2}{*}{$\hat{r}_{g}$} & \multicolumn{2}{c}{ Credible Sets } \\
\cline { 3 - 4 } & & Lower & Upper \\
\hline Weight-Chroma & $-0.169^{2}$ & -0.532 & 0.168 \\
Hue angle-Chroma & $-0.762^{1}$ & -0.901 & -0.616 \\
Firmness-L $\mathrm{L}^{*}$ & $-0.151^{2}$ & -0.555 & 0.236 \\
Firmness-a* & $0.254^{2}$ & -0.151 & 0.626 \\
Firmness-b* $^{*}$ & $0.069^{2}$ & -0.341 & 0.482 \\
Weight-L $^{*}$ & $0.518^{1}$ & 0.257 & 0.775 \\
Weight-a* & $-0.333^{1}$ & -0.652 & -0.003 \\
Weight- $^{*}$ & $0.131^{2}$ & -0.234 & 0.509 \\
\hline
\end{tabular}

${ }^{1}$ Significantly different from zero according to the credible set. ${ }^{2}$ Not significantly different from zero. ${ }^{3} \mathrm{~L}^{*}, \mathrm{a}^{*}, \mathrm{~b}^{*}$, Hue angle and Chroma are color parameters.

The results of single-trait regressions in a Bayesian framework (considering each locus as an explanatory variable) are shown in Table S4. For Bayesian bi-trait regressions, according to the Bayesian credible region, 5 (of 12) correlation estimates were significantly different from zero (Table 3). Interestingly, fruit weight and Hue showed a positive genetic association (significantly different from zero), which agreed with the existence of two pleiotropic loci (FvH4045 and CFACT084; Table 4) on linkage groups FG3A and FG2A/B/C with probabilities of the posterior estimates of 0.022 and $<0.001$, respectively (Table 4 ). Hue and Chroma showed a high and negative genetic correlation $\left(\hat{r}_{g}=-0.762\right)$, with no pleotropic locus (Table 3). Interestingly, the locus FvH4045 was also pleotropic between weight- $\mathrm{L}^{*}$ and weight- $\mathrm{a}^{*}$, with posterior probabilities of 0.008 and 0.04 , respectively. Moreover, these pairs of traits had significant genetic correlations between them $\left(\hat{r}_{g}=0.518\right.$ and -0.333 , respectively) (Table 3).

Table 4. Pleotropic loci that were significant among all the traits under study.

\begin{tabular}{ccccccc}
\hline \multirow{2}{*}{ Locus } & \multirow{2}{*}{ LG $^{\mathbf{1}}$} & \multirow{2}{*}{ Pair of Traits } & \multirow{2}{*}{ Estimate } & \multicolumn{2}{c}{ Credible Set } & \multirow{2}{*}{ pMCMC $^{2}$} \\
\cline { 5 - 6 } & & & & Lower & Upper & \\
\hline FvH4045 & FG3A & Weight-Hue angle & 1.31 & 0.31 & 2.38 & 0.022 \\
CFACT084 & FG2A/2B/2C & Weight-Hue angle & -2.05 & -3.03 & -0.99 & $<0.001$ \\
FvH4045 & FG3A & Weight-L & 1.47 & 0.34 & 2.48 & 0.008 \\
FvH4045 & FG3A & Weight-a*3 $^{*}$ & 1.18 & 0.07 & 2.39 & 0.044 \\
\hline
\end{tabular}

${ }^{1}$ Linkage group (LG) according to Sargent et al. [25]; ${ }^{2}$ Probability of the posterior estimates including zero; ${ }^{3} \mathrm{~L}^{*}, \mathrm{a}^{*}$ and Hue angle are color parameters; pMCMC: probability of the posterior estimates including zero.

In strawberry fruit, both in F. chiloensis and F. $\times$ ananassa, fresh weight and firmness were negatively correlated during fruit development and ripening $[7,26]$. In contrast, Fragaria species differed with respect to color acquisition during fruit ripening. In this sense, $F . \times$ ananassa ripe fruit ('Aromas') with a typically full red color presented Hue, $\mathrm{L}^{*}$ and $\mathrm{a}^{*}$ values of $30 \mathrm{~h}^{\circ}, 34 \mathrm{~h}^{\circ}$ and $35 \mathrm{~h}^{\circ}$ respectively [26], but in F. chiloensis $\mathrm{f}$. chiloensis ripe fruits, which present commonly a white color, the Hue, $\mathrm{L}^{*}$ and $\mathrm{a}^{*}$ values were $88 \mathrm{~h}^{\circ}, 60$ and 0 , respectively [27]. In the present research, we observed wide distributions for Hue, $L^{*}$ and $a^{*}$ values of the accessions' ripe fruits from approximately 27 to 82,28 to 63 , and 3 to 36, respectively (Figure 2, Table S5). This distribution is explained by the analysis of patagonica and chiloensis forms that presented white-pink and fully red fruits at the ripe stage, respectively. The positive genetic associations that present weight and Hue, and weight and $\mathrm{L}^{*}$, and the negative between weight and $a^{*}$ (Table 3 ) are due precisely to the fact that $\mathrm{f}$. chiloensis accessions showed simultaneously a high weight and white skin color (higher Hue and $L^{*}$ and lower a* values than f. patagonica accessions) (Figure 2, Table S5).

The discovery of genes and/or loci determining fruit quality traits has been a major scope of Fragaria mapping projects thus far [28]. For instance, Zorrilla-Fontanesi et al. [29] investigated the 
genetic control of agronomical and fruit quality traits in strawberries using an F1 population derived from an intraspecific cross between two contrasting selection lines. In such a study, many quantitative trait loci (QTL) controlling correlated traits were co-located, indicating linkage or pleiotropic effects of loci.

\section{Conclusions}

The results of the present research are promising and suggest that the genetic variation found among wild populations of $F$. chiloensis supports the idea of domestication and improvement of this crop for sustainable fruit production systems. Specifically, it is possible to infer that the use of this variation will serve to obtain short-term genetic advances, in pre-breeding programs of Chilean strawberries, focusing primarily on weight (productivity) and skin color variants between red and white, since these traits are important for the production and quality of strawberries, respectively. In fact, skin color would be a key trait for breeding purposes, due the importance for visual attraction and the diversity found in this species for this trait (especially in the color parameter $\mathrm{a}^{*}$ ). We emphasized the need to improve both the rate of flowering and fruit set, since these traits are the most limiting factors for productivity in most accessions. Finally, as a next step in this line of research, we plan to analyze other fruit quality-related traits in the germplasm collection such as soluble solids content, acidity and bioactive compounds.

Supplementary Materials: The following are available online at http://www.mdpi.com/2073-4395/9/9/506/s1, Table S1: Code, name, and geographic location of the different accessions of the germplasm collection of Fragaria chiloensis collected in south-central Chile and analyzed in the present research for fruit weight, firmness and color parameters during the growing season in 2015. Accessions are listed by latitude in increasing order. Table S2: List of the 39 SSR markers, including their respective primers, associated linkage groups, and references; Table S3: Summary of phenotypic values for seven fruit quality traits of 391 ramets from 36 accessions of $F$. chiloensis during the growing season in 2015; Table S4: Summary of single-trait regressions in a Bayesian framework (considering each locus as an explanatory variable). Significant loci according to pMCMC (probability of the posterior estimates including zero), for each trait in a single-trait model; Table S5: Phenotypic mean values for seven fruit quality traits of different $F$. chiloensis accessions during the growing season in 2015. Values correspond to mean \pm SD of at least three replicates (fruits).

Author Contributions: Conceptualization, F.M. and C.R.F.; methodology, F.M., P.E.Z. and C.R.F.; software, F.M.; validation, F.M., P.E.Z. and C.R.F.; formal analysis, F.M., P.E.Z. and C.R.F.; investigation, F.M., P.E.Z. and C.R.F.; resources, F.M. and C.R.F.; writing—original draft preparation, F.M.; writing-review and editing, F.M., P.E.Z. and C.R.F.; visualization, P.E.Z. and C.R.F.; supervision, C.R.F.; project administration, C.R.F.; funding acquisition, C.R.F.

Funding: This research was funded by the National Commission for Scientific and Technological Research (CONICYT, Chile), grants PIA/ACT-1110 to F.M. and C.R.F.; FONDECYT/Regular 1140663 and 1181310 to C.R.F.; and FONDECYT/Regular 1170695 to F.M.

Acknowledgments: P.E.Z. acknowledges to Universidad de Talca for a doctoral scholarship.

Conflicts of Interest: The authors declare no conflict of interest. The funders had no role in the design of the study, in the collection, analyses, or interpretation of data, in the writing of the manuscript, or in the decision to publish the results.

\section{References}

1. Retamales, J.B.; Caligari, P.D.S.; Carrasco, B.; Saud, G. Current Status of the Chilean Native Strawberry and the Research Needs to Convert the Species into a Commercial Crop. HortScience 2005, 40, 1633-1634. [CrossRef]

2. Mora, F.; Concha, C.M.; Figueroa, C.R. Bayesian inference of genetic parameters for survival, flowering, fruit set, and ripening in a germplasm collection of chilean strawberry using threshold models. J. Am. Soc. Hortic. Sci. 2016, 141, 285-291. [CrossRef]

3. Zorrilla-Fontanesi, Y.; Rambla, J.L.; Cabeza, A.; Medina, J.J.; Sánchez-Sevilla, J.F.; Valpuesta, V.; Botella, M.A.; Granell, A.; Amaya, I. Genetic analysis of strawberry fruit aroma and identification of O-methyltransferase FaOMT as the locus controlling natural variation in mesifurane content. Plant Physiol. 2012, 159, 851-870. [CrossRef] [PubMed] 
4. Davik, J.; Honne, B.I. Genetic variance and breeding values for resistance to a wind-borne disease [Sphaerotheca macularis (Wallr. ex Fr.)] in strawberry (Fragaria $\times$ ananassa Duch.) estimated by exploring mixed and spatial models and pedigree information. Appl. Genet. 2005, 111, 256-264. [CrossRef] [PubMed]

5. Mishra, P.; Ram, R.B.; Kumar, N. Genetic variability, heritability, and genetic advance in strawberry (Fragaria $\times$ ananassa Duch.). Turk. J. Agric. 2015, 39, 451-458. [CrossRef]

6. Ather-uz-Zaman; Al-Khayri, J.M.; Islam, R. Genetic Improvement of Strawberry (Fragaria $\times$ Ananassa Duchesne). In Advances in Plant Breeding Strategies: Fruits; Al-Khayri, J.M., Jain, S.M., Johnson, D.V., Eds.; Springer International Publishing: Berlin/Heidelberg, Germany, 2018; pp. 217-275.

7. Figueroa, C.R.; Pimentel, P.; Gaete-Eastman, C.; Moya, M.; Herrera, R.; Caligari, P.D.S.; Moya-León, M.A. Softening rate of the Chilean strawberry (Fragaria chiloensis) fruit reflects the expression of polygalacturonase and pectate lyase genes. Postharvest Biol. Technol. 2008, 49, 210-220. [CrossRef]

8. Fuentes, L.; Figueroa, C.R.; Valdenegro, M. Recent advances in hormonal regulation and cross-talk during non-climacteric fruit development and ripening. Horticulturae 2019, 5, 45. [CrossRef]

9. Salvatierra, A.; Pimentel, P.; Moya-Leon, M.A.; Caligari, P.D.S.; Herrera, R. Comparison of transcriptional profiles of flavonoid genes and anthocyanin contents during fruit development of two botanical forms of Fragaria chiloensis ssp. chiloensis. Phytochemistry 2010, 71, 1839-1847. [CrossRef]

10. Oñate, F.A.; Hasbún, R.; Mora, F.; Figueroa, C.R. Linkage disequilibrium and population structure in Fragaria chiloensis revealed by SSR markers transferred from commercial strawberry. Acta Sci. Agron. 2018, 40, e34966. [CrossRef]

11. McGuire, R.G. Reporting of objective color measurements. HortScience 1992, 27, 1254-1255. [CrossRef]

12. Torres, L.G.; Rodrigues, M.C.; Lima, N.L.; Trindade, T.F.H.; e Silva, F.F.; Azevedo, C.F.; DeLima, R.O. Multi-trait multi-environment Bayesian model reveals $\mathrm{G} \times \mathrm{E}$ interaction for nitrogen use efficiency components in tropical maize. PLoS ONE 2018, 13, e0199492. [CrossRef]

13. Falconer, D.S. Introduction to Quantitative Genetics; Oliver and Boyd: Edinburgh, UK, 1960.

14. Valenzuela, C.E.; Ballesta, P.; Maldonado, C.; Baettig, R.; Arriagada, O.; Sousa Mafra, G.; Mora, F. Bayesian mapping reveals large-effect pleiotropic QTLs for wood density and slenderness index in 17-year-old trees of Eucalyptus cladocalyx. Forests 2019, 10, 241. [CrossRef]

15. Hadfield, J.D. MCMC methods for multi-response generalized linear mixed models: The MCMCglmm R package. J. Stat. Softw. 2010, 33, 1-22. [CrossRef]

16. Becerra, V.; Paredes, M.; Lavín, A. Biochemical and molecular diversity in the Chilean strawberry and its implications for plant breeding. HortScience 2005, 40, 1642-1643. [CrossRef]

17. Carrasco, B.; Garcés, M.; Rojas, P.; Saud, G.; Herrera, R.; Retamales, J.B.; Caligari, P.D.S. The chilean strawberry [Fragaria chiloensis (L.) Duch.]: Genetic diversity and structure. J. Am. Soc. Hortic. Sci. 2007, 132, 501-506. [CrossRef]

18. Naegele, R.P.; Mitchell, J.; Hausbeck, M.K. Genetic diversity, population structure, and heritability of fruit traits in Capsicum annuum. PLoS ONE 2016, 11, e0156969. [CrossRef]

19. Azodanlou, R.; Darbellay, C.; Luisier, J.L.; Villettaz, J.C.; Amadò, R. Quality assessment of strawberries (Fragaria species). J. Agric. Food Chem. 2003, 51, 715-721. [CrossRef]

20. Capocasa, F.; Scalzo, J.; Mezzetti, B.; Battino, M. Combining quality and antioxidant attributes in the strawberry: The role of genotype. Food Chem. 2008, 111, 872-878. [CrossRef]

21. Wang, J.; Yue, C.; Gallardo, K.; McCracken, V.; Luby, J.; McFerson, J. What consumers are looking for in strawberries: Implications from market segmentation analysis. Agribusiness 2017, 33, 56-69. [CrossRef]

22. Whitaker, V.M.; Osorio, L.F.; Hasing, T.; Gezan, S. Estimation of genetic parameters for 12 fruit and vegetative traits in the University of Florida strawberry breeding population. J. Am. Soc. Hortic. Sci. 2012, 137, 316-324. [CrossRef]

23. Mori, T. Heritability and selection effectiveness for fruit firmness in strawberry. J. Jpn. Soc. Hortic. Sci. 2000, 69, 90-96. [CrossRef]

24. Masny, A.; Pruski, K.; Żurawicz, E.; Mądry, W. Breeding value of selected dessert strawberry (Fragaria $\times$ ananassa Duch.) cultivars for ripening time, fruit yield and quality. Euphytica 2016, 207, 225-243. [CrossRef]

25. Sargent, D.J.; Passey, T.; Šurbanovski, N.; Lopez Girona, E.; Kuchta, P.; Davik, J.; Harrison, R.; Passey, A.; Whitehouse, A.B.; Simpson, D.W. A microsatellite linkage map for the cultivated strawberry (Fragaria $\times$ ananassa) suggests extensive regions of homozygosity in the genome that may have resulted from breeding and selection. Appl. Genet. 2012, 124, 1229-1240. [CrossRef] [PubMed] 
26. Garrido-Bigotes, A.; Figueroa, P.M.; Figueroa, C.R. Jasmonate metabolism and its relationship with abscisic acid during strawberry fruit development and ripening. J. Plant Growth Regul. 2018, 37, 101-113. [CrossRef]

27. Concha, C.M.; Figueroa, N.E.; Poblete, L.A.; Oñate, F.A.; Schwab, W.; Figueroa, C.R. Methyl jasmonate treatment induces changes in fruit ripening by modifying the expression of several ripening genes in Fragaria chiloensis fruit. Plant Physiol. Biochem. 2013, 70, 433-444. [CrossRef] [PubMed]

28. Mohamed, A.R.M.A.W.; Jęcz, T.; Korbin, M. The history of genome mapping in Fragaria spp. J. Hortic. Res. 2014, 22, 93-103. [CrossRef]

29. Zorrilla-Fontanesi, Y.; Cabeza, A.; Domínguez, P.; Medina, J.J.; Valpuesta, V.; Denoyes-Rothan, B.; Sánchez-Sevilla, J.F.; Amaya, I. Quantitative trait loci and underlying candidate genes controlling agronomical and fruit quality traits in octoploid strawberry (Fragaria $\times$ ananassa). Appl. Genet. 2011, 123, 755-778. [CrossRef] [PubMed]

(C) 2019 by the authors. Licensee MDPI, Basel, Switzerland. This article is an open access article distributed under the terms and conditions of the Creative Commons Attribution (CC BY) license (http://creativecommons.org/licenses/by/4.0/). 